\title{
Driving factors of the thermal efficiency of ground source heat pump systems with vertical boreholes in Chongqing by experiments
}

Article

Accepted Version

Creative Commons: Attribution-Noncommercial-No Derivative Works 4.0

Li, B., Zheng, M., Shahrestani, M. and Zhang, S. (2020)

Driving factors of the thermal efficiency of ground source heat pump systems with vertical boreholes in Chongqing by experiments. Journal of Building Engineering, 28. 101049. ISSN 2352-7102 doi:

https://doi.org/10.1016/j.jobe.2019.101049 Available at https://centaur.reading.ac.uk/88128/

It is advisable to refer to the publisher's version if you intend to cite from the work. See Guidance on citing.

To link to this article DOI: http://dx.doi.org/10.1016/j.jobe.2019.101049

Publisher: Elsevier

All outputs in CentAUR are protected by Intellectual Property Rights law, including copyright law. Copyright and IPR is retained by the creators or other copyright holders. Terms and conditions for use of this material are defined in the End User Agreement. 


\section{www.reading.ac.uk/centaur}

\section{CentAUR}

Central Archive at the University of Reading

Reading's research outputs online 


\title{
Driving factors of the thermal efficiency of ground source heat pump systems with vertical boreholes in Chongqing by experiments
}

\author{
Baiyi $\mathrm{Li}^{\mathrm{a}, *}$, Min Zheng ${ }^{\mathrm{b}}$, Mehdi Shahrestani ${ }^{\mathrm{c}}$, Shaoxing Zhang ${ }^{\mathrm{d}}$ \\ ${ }^{a}$ Faculty of Architecture, Southwest Jiaotong University, Sichuan 600000, China \\ ${ }^{b}$ Sichuan Institute of Building Science Research Ltd, Sichuan, 600000, China \\ ${ }^{c}$ School of the Built Environment, University of Reading, RG6 6AW Reading, UK \\ ${ }^{d}$ Jiangsu Zhongyinghai Green Building Industry Research Institute, Haimen 226100, China
}

\begin{abstract}
Over the past years, the technology of Ground-coupled Heat Pump (GCHP) has been utilized in many countries due to its capabilities in providing sustainable heating and cooling. Previous studies in this field have shown that the thermal efficiency of GCHP is closely related to the properties of soil. However, the way in which the system should operate to provide the highest possible energy efficiency considering the thermal characteristics of the soil, needs further investigation. Therefore, the aim of this research is to investigate the factors that influence the energy performance of heat pump system, and to identify the key factors that contribute to the high energy performance of the system. This has been achieved through a series of experimental studies and on-site monitoring and data analysis for GCHP with vertical ground source heat exchanger in Chongqing, China. A set of experiments were set up to assess the influence of variations in the fluid temperature entering the ground heat exchanger, buried depth and operation mode on the energy performance of the GCHP system. The outcomes of this study have shown that, the operation mode and the depth of buried tube have more influence than other factors, intermittent operation mode and $60 \mathrm{~m}$ buried tube depth are preferred to choose firstly. Higher inlet
\end{abstract}

\footnotetext{
${ }^{*}$ Correspondence to: Faculty of Architecture, Southwest Jiaotong University, Sichuan 600000, China

Email address: $735698217 @ q q . \operatorname{com}$ (Baiyi Li)
} 
temperature, lower inflow velocity and casing/double-U type pipes will help to enhance the energy efficiency of GCHP.

Keywords: ground-coupled heat pumps, field measurement, influential parameter, energy efficiency

\section{Introduction}

As one important component in energy supply system, renewable energy technologies play a strategic role in transformation of energy systems and mitigation of climate change in many countries [1]. Replacing fossil fuel by re-

5 newable energy is one of the key methods to promote sustainability in building and environments 2] that can potentially reduce the energy related greenhouse gas (GHGs) emissions associated with the operation of buildings [3]. In 2007, China State Council released Mid- and Long-Term Development Plan for Renewable Energy, with target of pushing usage of renewable energy sources in primary energy consumption to $10 \%$ in 2010 and $15 \%$ in 2020 4. Renewable energies contributed to about $9.1 \%$ of Chinas primary energy supply in 2010 , which constituted of hydro power, biomass, solar, wind and geothermal energy with proportion of $78 \%, 9 \%, 7 \%, 5 \%$ and $1 \%$ respectively [5]. As geothermal energy currently only contributes $1 \%$ of renewable energy usage in China, there 15 is huge potential for more projects to employ geothermal power plants for energy generation in near future [6]. Ground-coupled heat pumps (GCHP) is a kind of geothermal power plant that utilizes ground as heat-source or sink. As ground temperature below a certain depth remains nearly constant throughout the year, it provides a great opportunity for GCHP systems to employ this theoretically stable temperature to respond to the heating and cooling demands of buildings [7].

When GCHP system is operating for cooling/heating, the thermal fluid circulating inside the pipes are responsible for extracting/rejecting heat from/to the building and rejecting/extracting it to ground [8], so the characteristics of the thermal fluid can significantly influence the overall energy performance of 
the system. Zhao et al. 9] found that the best coefficient of performance (COP) of GCHP can only be achieved under certain optimal combination of fluid flow rate and compressor operational frequencies. Han et al. [10] used commercial software Fluent to discuss the design errors of GCHP system under ASHRAE method, they found that high fluid velocity will lead to greater error in design and modelling of the system. To better understand the governing equations of ground heat transfer and heat pump performance, Bernier [11] coupled fluid loop temperature to the solving process of simulation and obtained annual energy consumption of heat pump more accurately and rapidly. You et al. [12] developed a hybrid GCHP system compensated by thermosyphon (HCUT) to reheat the thermal fluid entering evaporator of heat pump during heating period. Their results indicated that annual COP of HCUT-GCHP system was enhanced to $2.48 \sim 2.61$ from $1.82 \sim 2.45$. Wei et al. [13] discussed the effects of outlet water temperature on GCHP performance through a 3D numeral model using Fluent software together with an experimental case study. They found that the influence of outlet water temperature on heat transfer calculation contributed greatly to the accurate prediction of heat transfer performance. Shang et al. 14 presented an intermittent experiment under heating mode to study influential factors for GCHP systems and indicated that higher inlet flow rate 45 will improve the rate of heat exchange due to aggravation of flow turbulence in pipes. Zhou et al. [15] discussed the fluid characteristics in single- $U$ and double-U pipes of GCHP system in Fluent and recommended single-U requires higher fluid velocity.

One advantage of GCHP system is that, under certain depth, the ground temperature is higher/lower than ambient temperature in winter/summer [16], so depth of burial pipes affects GCHP performance seriously. Wang et al. [17] analyzed the effects of Borehole Heat Exchangers (BHE) depth using Computational Fluid Dynamic (CFD) technique and suggested that depth of vertical boreholes should be more than $70 \mathrm{~m}$ to maintain a high long-term energy efficien-

55 cy of the system. Luo [18] used experimental measurements as well as numerical modeling to examine how pipe burial depth and pipe insulation impact GCHP 
performance, and concluded that larger burial depth can reduce energy loss. Esen and Turgut [19] carried out experimental studies about drilled holes at three different depths $(30,60$, and $90 \mathrm{~m})$ and found a deeper depth led to better 60 COP performance, and specifically the borehole depth contributes to $67.77 \%$ of COP performance, condenser outlet-inlet temperatures contribute to $12.74 \%$ and $8.28 \%$, evaporator inlet-outlet temperatures contribute to $3.86 \%$ and $5.89 \%$. However, a deeper borehole depth is associated with more initial costs (drilling, excavation, etc.) but less operation cost (energy), so the economic applicability needs to be considered carefully under project budget [20. Chen et al. 21] simulated GCHP performance for boreholes with 60 to $100 \mathrm{~m}$ depth through five case studies and found that depth of $70 \mathrm{~m}$ would be optimal under the tradeoff between heat exchange rate and initial cost of Ground Heat Exchangers (GHE) system.

The accurate performance prediction of complex heating systems (e.g. GCHP) is not always easy, such as a high labelled device could have a low efficiency but under a perfect operation stategy by craftsmen, a low labelled device might achieve high efficiency [22]. The operation stategies of GCHP systems are usually divided into intermittent and continuous types. The controllable intermittent technology could enhance the heat transfer between ground source heat exchanger and soil and reduce heat transfer attenuation [23, meanwhile weaken the extreme temperature around GHE system and reach a temperature restoration [24. Zhang et al. 25] used an hourly simulation method to assess the energy performance of a GCHP in an office building. Results showed the COP of intermittent mode will be increased by $21.87 \%$ during a three-month operation compared with continuous mode. Zeng et al. [26] applied on-site experiments on GCHP test in a karst region. The outcomes of this study revealed that the COP of heat pump (COPhp) and overall system (COPsys) under intermittent mode compare to the continuous mode was improved by $24.2 \%$ and ${ }_{85} \quad 23.0 \%$ in cooling operation while $28.6 \%$ and $39.3 \%$ in heating operation respectively. Man et al. 27] carried out a set of experimental studies to investigate the actual performance of GCHP system under both continues and intermittent 
modes. The outcomes of this study showed $11.57 \%$ COP improvement after 40-hour cooling provision and 9.47\% COP improvement after 100-hour heating provision. Their results also showed that the advantages of intermittent mode will become more remarkable with increase of operation time.

So far, number of studies have been carried out to investigate the influence of individual factors to the total energy performance of GCHP systems. Many of these GCHP studies were carried out using numerical modeling and simulations. Therefore, the accuracy of results and applicability of their approach for engineering practices need to be further studied by experimental data [28]. Some researchers already deployed on-site experiments [10] 16] 17, but our studies exhibit more comprehensive working conditions.

In this paper, a set of experimental cases were studied to explore the actual performance of GCHP systems in Chongqing, China. The aim of this research is to investigate the factors that influence the energy performance of heat pump system, and to identify the key factors that contribute to the high energy performance of the system. More specifically, this research is to study the influences of inflow temperature, inflow velocity, depth of burial pipes and operation modes on energy efficiency of GCHP.

\section{Experiment device and method}

\subsection{Experimental design}

This study is carried out through the experimental study of a vertical ground source heat exchanger. The type of soil is silty clay, with dry density of thermal diffusivity of $0.68 \sim 1.43 \times 10^{-6} \mathrm{~m}^{2} / \mathrm{s}$. There are 12 drilling wells, labeled with serial number from 1 to 12 . The first six wells are double U-type buried pipes, the last three wells are casing-type buried pipes and the rest of wells are single U-type buried wells. All the wells are backfilled by mixture of cement, and $80 \mathrm{~m}$. The diameter of the drilling well is $220 \mathrm{~mm}$. The inner and external 
diameters for U-type pipe are $32 \mathrm{~mm}$ and $40 \mathrm{~mm}$, while for casing pipe are 50 $\mathrm{mm}$ and $60 \mathrm{~mm}$. Water is the thermal fluid circulating inside the pipe.

The experiment is carried out to measure the wall surface temperature of buried pipes together with the temperature and flow rate of the thermal fluid in the ground source heat exchanger. These factors are measured for the vertical heat exchangers number 3, 6, 9 and 12 .

Screw type heat pump unit is adopted for the cold and heat source over ground. The heat pump system consists of 6 double-U units, 3 single- $U$ units and 3 casing type units, as shown in Fig. 1. The cooling capacity per unit is $2300 \mathrm{KW}$ while the heating capacity for single unit is $2500 \mathrm{KW}$.

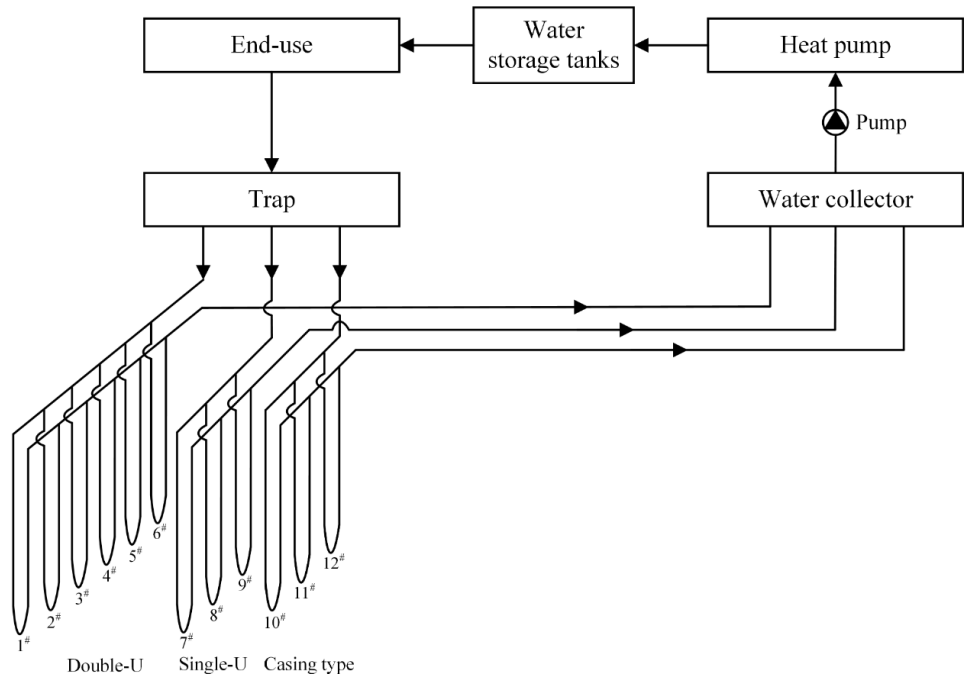

Figure 1: Map of heat pump system

The specification of the instrument used to measure temperature and flow rate are provided in Table 1

This experiment is aimed to study the energy performances of the vertical ground source heat exchanger in different working conditions. It is well known that the heat exchange capacity will gradually decline during the continuous operation of the heat pump system. Therefore, it is crucial to examine different heat-transfer characteristics arising from accumulation of heat in ground layers. 
Table 1: Specifications of the instruments

\begin{tabular}{cccc}
\hline Name & Type & Range & Precision \\
\hline $\begin{array}{c}\text { Thermal resistance meter } \\
\text { to measure temperature }\end{array}$ & PT100 & $-20 \sim 100{ }^{\circ} \mathrm{C}$ & $0.01{ }^{\circ} \mathrm{C}$ \\
Flow meter & LZB-40 & $160 \sim 1600 \mathrm{~L} / \mathrm{h}$ & $0.1 \mathrm{~L} / \mathrm{h}$ \\
\hline
\end{tabular}

To better quantify the thermal characteristics of ground source heat exchangresistance of the heat exchanger as well as the heat accumulation phenomena 
in the ground. The energy efficiency coefficient was proposed to quantify the energy efficiency of a heat exchanger. The energy efficiency coefficient $\mathrm{E}$ of Utype buried heat exchanger is the ratio between the actual heat exchange $(\mathrm{Q})$ of buried heat exchanger and the maximum theoretic heat exchange $(\bar{Q})$, which can be represented as:

$$
\left.E=\frac{Q}{\bar{Q}}=\frac{G c\left(T_{f} \text { in }-T_{f} \text { out }\right)}{G c\left(T_{f} \text { in }-T_{0}\right)}=\frac{\left(T_{f} \text { in }-T_{f} \text { out }\right)}{\left(T_{f} \text { in }-T_{0}\right)}\right)
$$

Where, $\mathrm{T}_{f}$ in, $\mathrm{T}_{f}$ out, $\mathrm{T}_{0}$, respectively stand for the fluid inflow temperature, fluid outlet temperature and the initial temperature of the rock and soil body temperature $\left({ }^{\circ} \mathrm{C}\right) ; \mathrm{G}$ refers to the mass flow rate of fluid inside the buried pipes $(\mathrm{kg} / \mathrm{s})$; and c refers to the specific heat capacity of the fluid inside the buried pipes $\left(\mathrm{J} / \mathrm{kg} \cdot{ }^{\circ} \mathrm{C}\right)$.

The energy efficiency coefficient of buried pipes is a dimensionless parameter, where the lower the energy efficiency coefficient is, the ability of heating exchanging will be lower. In contrary, the temperature of outlet fluid is near to the initial temperature of soil, the energy efficiency coefficient is higher relatively, the performance of the heat pump is better.

\subsubsection{Utility period}

For ground source heat exchanger, the continuous heat exchange load will lead to the accumulation of heat in the ground that results in an increase of ground temperature and consequently the decline in the energy efficiency coefficient of the heat exchanger. It can be estimated that the heat transfer capacity for buried heat exchanger will continue to decrease during the continuous operation of the heat pump system, till the energy efficiency of heat exchanger can not reach design demands. The utility period is a factor to examine the energy-efficient operation of the heat pump system. It is represented by the period in which the ground source heat exchanger is able to operate under a certain temperature difference of the working fluid entering and leaving the heat exchanger. 


\section{Data analysis and discussion}

The experiment results will show the changes of energy efficiency coefficient and utility period in cases of different inflow temperatures, inflow velocities, depths of burying and operation modes to analyze the influences of various working conditions on the heat exchange characteristics of buried pipes and its surrounding ground.

\subsection{The influences of inflow temperature for buried pipe on the energy efficiency} coefficient and utility period

This experiment is about the study on working conditions in both winter and summer seasons. In experiment for summer season, the inflow temperature of buried heat exchanger is maintained within the range of $30 \sim 35{ }^{\circ} \mathrm{C}$, the flow velocity inside the pipe kept as $0.682 \mathrm{~m} / \mathrm{s}(1200 \mathrm{~L} / \mathrm{h})$. While in experiment for winter season, the inflow temperature of buried pipe is kept within the range of $8 \sim 10{ }^{\circ} \mathrm{C}$ with the flowrate of the thermal fluid equal to $800 \mathrm{~L} / \mathrm{h}$. The initial temperatures for the body of rock and soil in both conditions are around 16.5 ${ }^{\circ} \mathrm{C}$.

The curve of experiment results for energy efficiency coefficient in different working conditions are illustrated in Figs. 2 and 3 respectively for summer and winter. In addition, Table 2 shows the changes of utility period in different working conditions.

Experiment results in Figs. 2 and 3 show that with the same initial temperature of the ground, energy efficiency coefficient for buried heat exchanger 


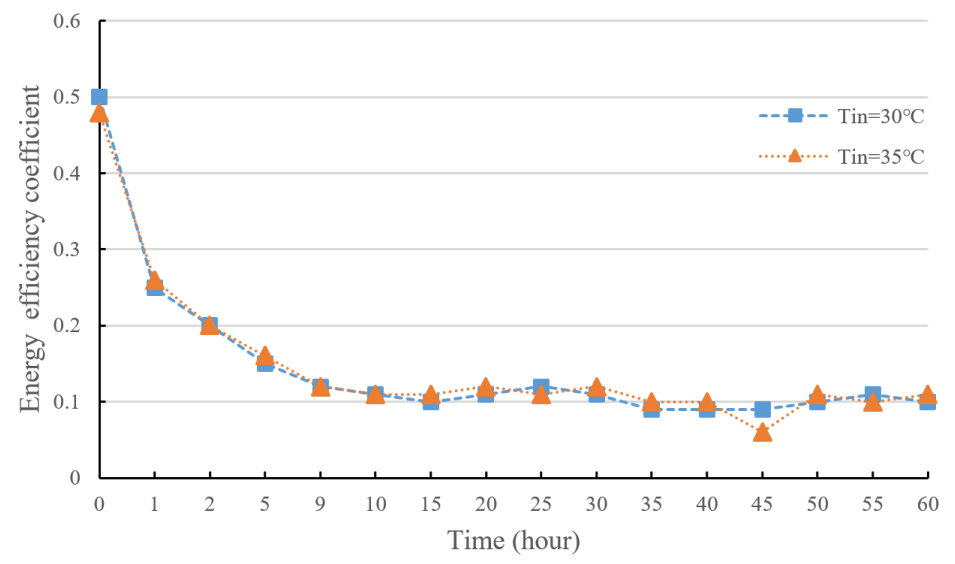

Figure 2: Energy efficiency coefficient of the vertical ground source heat exchanger under different inflow temperature of the thermal fluid in summer

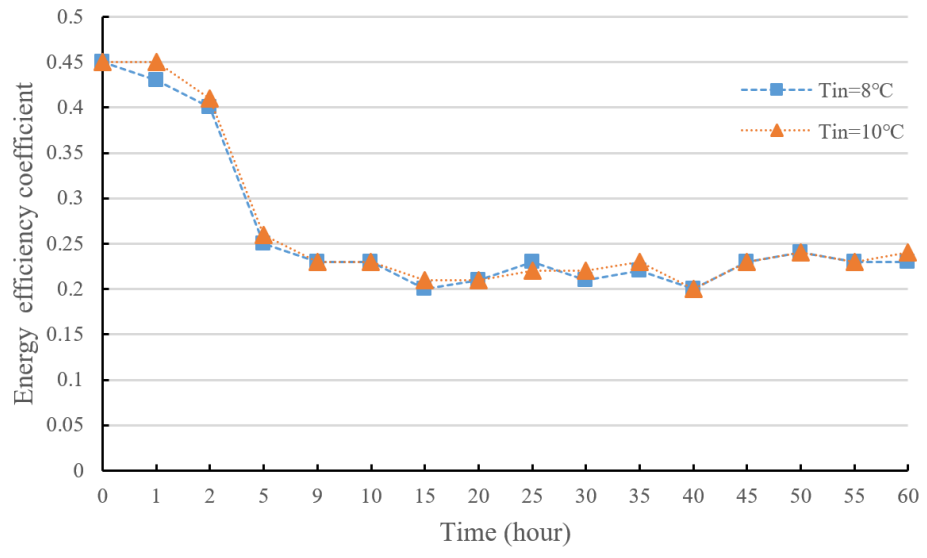

Figure 3: Energy efficiency coefficient of the vertical ground source heat exchanger under different inflow temperature of the thermal fluid in winter 
Table 2: Utility period of the vertical ground source heat exchanger under different inflow temperature of thermal fluid (Unit: hour)

Temperature difference between the

Inflow temperatures for the buried pipe working fluid entering and leaving the heat exchanger (Utility period) $\Delta \mathrm{T}=4{ }^{\circ} \mathrm{C} \quad \Delta \mathrm{T}=3{ }^{\circ} \mathrm{C} \quad \Delta \mathrm{T}=2{ }^{\circ} \mathrm{C}$

$\begin{array}{cccc}35{ }^{\circ} \mathrm{C} & 0.7 & 2.7 & 14 \\ 30{ }^{\circ} \mathrm{C} & 0.3 & 0.8 & 4.4 \\ 10{ }^{\circ} \mathrm{C} & 0.2 & 0.4 & 3.7 \\ 8{ }^{\circ} \mathrm{C} & 0.6 & 0.8 & 9.7\end{array}$

is reduced by time under different inflow temperatures, regardless of winter or summer conditions. However, in different working conditions in winter or summer season, the energy efficiency coefficient will not vary according to the inflow temperature of buried pipe. Despite the energy efficiency coefficient is not influenced by the changes in temperature of the thermal fluid entering the heat exchanger, the utility period has been significantly influenced by changes in temperature of the thermal fluid entering the heat exchanger (Table 2).

In order to manifest the high-efficient operation period of the system in different inflow temperature conditions, the experiment has measured the utility period under four specific inflow temperatures: $35{ }^{\circ} \mathrm{C}$ and $30{ }^{\circ} \mathrm{C}$ represented summer condition, $10{ }^{\circ} \mathrm{C}$ and $8{ }^{\circ} \mathrm{C}$ represented winter condition. The utility period has been examined when temperature differences between the working fluid entering and leaving the heat exchanger are $4{ }^{\circ} \mathrm{C}, 3{ }^{\circ} \mathrm{C}$ and $2{ }^{\circ} \mathrm{C}$ respectively.

The experiment results (Table 2) illustrate that under same temperature difference between the working fluid entering and leaving the heat exchanger, the higher/lower the inflow temperature is, the longer/shorter the utility period will become in heating/cooling mode of operation. 
3.2. The influences of buried inflow velocity on the energy efficiency coefficient and utility period

In experiment for summer season, the inflow temperature of buried pipe was controlled within $35 \pm 0.5^{\circ} \mathrm{C}$, with flow velocity inside the pipe as $1200 \mathrm{~L} / \mathrm{h}$ and $1600 \mathrm{~L} / \mathrm{h}$ respectively. In experiment for winter season, the inflow temperature the pipes as $800 \mathrm{~L} / \mathrm{h}$ and $1000 \mathrm{~L} / \mathrm{h}$. The initial temperature of the ground was $16.5^{\circ} \mathrm{C}$.

Experiment results (Figs. 4 and 5) show that with the same initial temperature for the ground, the energy efficiency coefficient for buried heat exchanger and summer conditions. In both summer and winter seasons, with different flowrates, the higher flowrate will lead to lower energy efficiency coefficient (Figs. 4 and 5 .

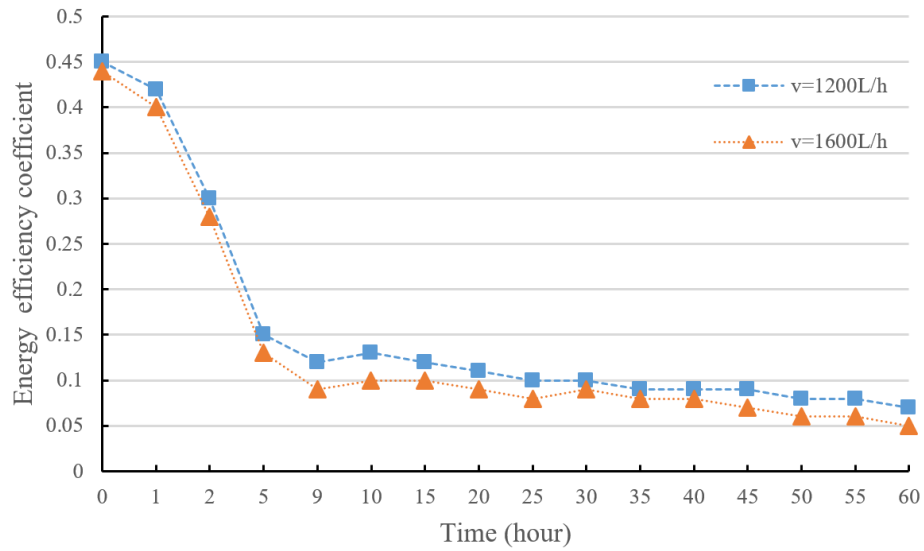

Figure 4: Energy efficiency coefficient of the vertical ground source heat exchanger under different flowrate of the thermal fluid in summer

The temperature difference between the thermal fluid entering and leaving the ground source heat exchanger decreases by time which is relevant to the utility period under each condition. In summer, the utility period with the flowrate of thermal fluid equal to $1600 \mathrm{~L} / \mathrm{h}$ is longer than the situation where it 


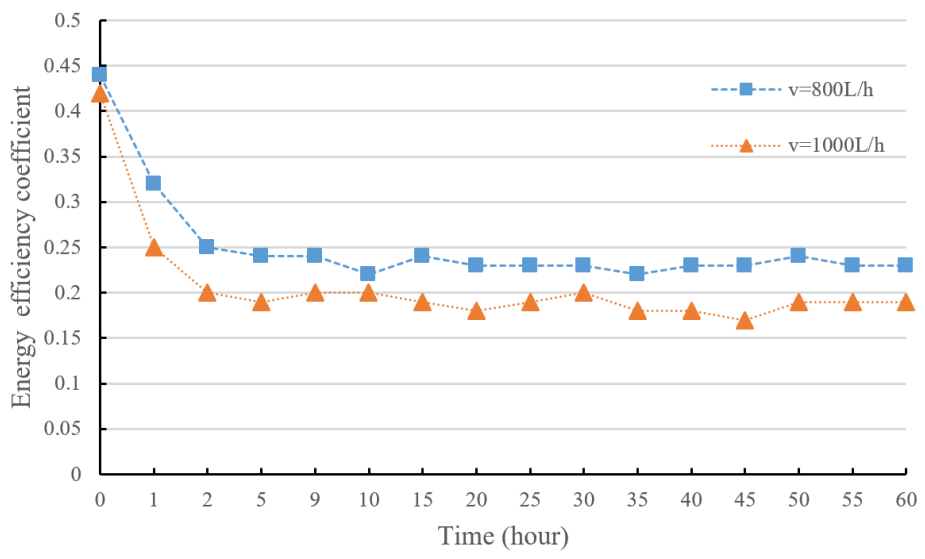

Figure 5: Energy efficiency coefficient of the vertical ground source heat exchanger under different flowrate of the thermal fluid in winter

is reduced to $1200 \mathrm{~L} / \mathrm{h}$ (Table 3). In winter, the utility period with the flowrate of thermal fluid equal to $800 \mathrm{~L} / \mathrm{h}$ is longer than the situation where it is increased to $1000 \mathrm{~L} / \mathrm{h}$ (Table 3). The utility period in summer is obviously lower than that for the winter, which is because that the temperature difference between inflow temperature of buried pipes and initial temperature of ground is equal to $21{ }^{\circ} \mathrm{C}$, which is far higher than $9{ }^{\circ} \mathrm{C}$ for winter. High inflow temperature will ensure greater heat exchange power and prolong utility period.

Table 3: Utility period of the vertical ground source heat exchanger under different flowrate of thermal fluid velocities (Unit: hour)

\begin{tabular}{cccc}
\hline Inflow velocity for buried pipes & $\Delta \mathrm{T}=4{ }^{\circ} \mathrm{C}$ & $\Delta \mathrm{T}=3{ }^{\circ} \mathrm{C}$ & $\Delta \mathrm{T}=2{ }^{\circ} \mathrm{C}$ \\
\hline $1600 \mathrm{~L} / \mathrm{h}$ & 0.5 & 2.2 & 9.1 \\
$1200 \mathrm{~L} / \mathrm{h}$ & 0.7 & 3.2 & 45 \\
$1000 \mathrm{~L} / \mathrm{h}$ & 0.2 & 0.4 & 1.9 \\
$800 \mathrm{~L} / \mathrm{h}$ & 0.3 & 1.0 & 9.8 \\
\hline
\end{tabular}



ground source heat exchanger is, the greater the energy efficiency coefficient will become. That is to say, in summer and winter, the energy efficiency coefficient for the well with $60 \mathrm{~m}$ depth is higher than that for the well with depth of 40 m.

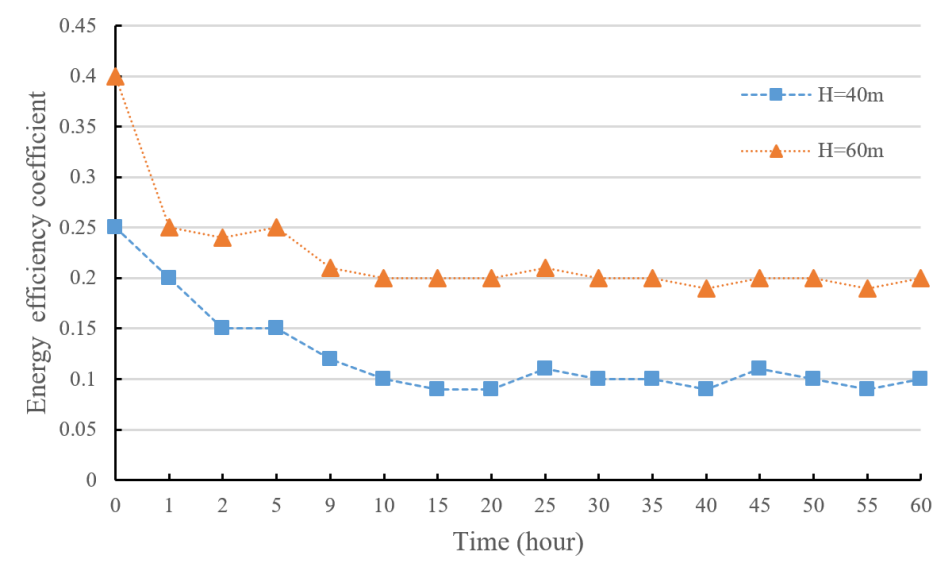

Figure 6: Energy efficiency coefficient of the vertical ground source heat exchanger under different buried depths in summer

As shown in Figs. 6 and 7 the difference between the temperature of thermal fluid entering and leaving the ground source heat exchanger is reduced by time. In both summer and winter seasons, the utility period for the 60 -meter-depth 


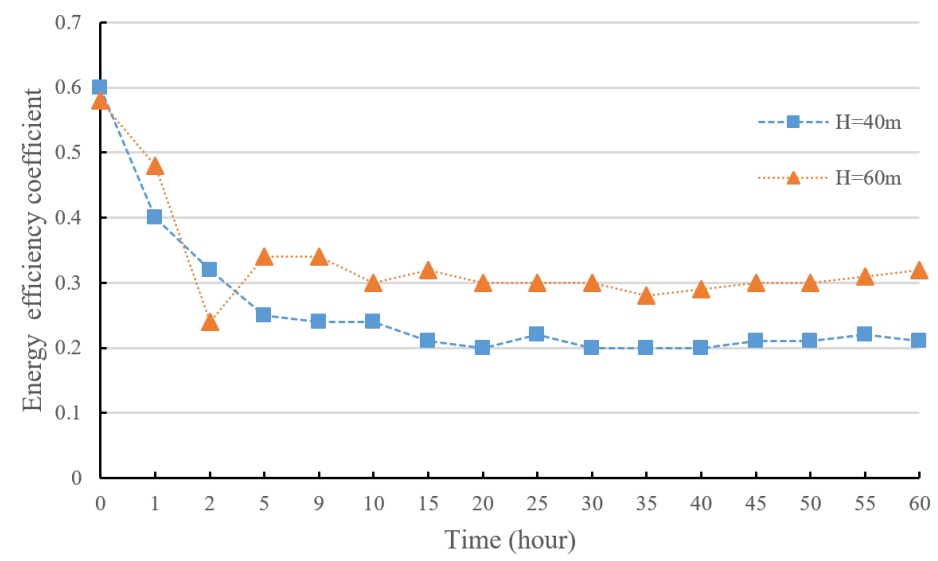

Figure 7: Energy efficiency coefficient of the vertical ground source heat exchanger under different buried depths in winter

well is significantly longer than the well with a depth of $40 \mathrm{~m}$, as shown in Table 4.

Table 4: Utility period of the vertical ground source heat exchanger under different depths (Unit: hour)

\begin{tabular}{cccc}
\hline Buried depth & $\Delta \mathrm{T}=4{ }^{\circ} \mathrm{C}$ & $\Delta \mathrm{T}=3{ }^{\circ} \mathrm{C}$ & $\Delta \mathrm{T}=2{ }^{\circ} \mathrm{C}$ \\
\hline $60 \mathrm{~m}$ (summer) & 3.3 & 11 & Up to 68 hours \\
$40 \mathrm{~m}$ (summer) & 0.9 & 3 & 12 \\
$60 \mathrm{~m}$ (winter) & 0.6 & 1.5 & Up to 69 hours \\
$40 \mathrm{~m}$ (winter) & 0.5 & 1.0 & 10 \\
\hline
\end{tabular}

As shown in Table 4, the endless increase of pipe length will not lead to a very high utility period, so the pipe length and utility period should be balanced carefully. Otherwise, it may pay great economic cost and still can not have a longer utility period.

\subsection{The influences of operation mode on the energy efficiency coefficient and} utility period

This experiment is carried out in a summer working condition, analyzing the heat exchange characteristics of buried ground source heat exchanger in 
intermittent alternative operation mode and continuous running mode. In experiment, the system was running in an intermittent alternative operation mode for $72 \mathrm{~h}$, maintaining the inflow temperature within $35 \pm 0.5^{\circ} \mathrm{C}$. Then stop the running for $72 \mathrm{~h}$ and then start a second operation for $72 \mathrm{~h}$, when the inflow temperature should be kept within $32 \pm 0.5^{\circ} \mathrm{C}$. The flowrate of thermal fluid was equal to $1200 \mathrm{~L} / \mathrm{h}$ and the initial temperature of the ground was equal to $16.5^{\circ} \mathrm{C}$. In continuous running mode, the system was running with the inflow temperature within the range of $35 \pm 0.5^{\circ} \mathrm{C}$ for $72 \mathrm{~h}$ and then continued to run another $72 \mathrm{~h}$ with the inflow temperature of $32 \pm 0.5^{\circ} \mathrm{C}$. In practice, mixing GCHP with auxiliary cold or heat equipment will slow down the effect of cold and heat accumulation. Of course, the length of required intermittent time and corresponding system efficiency are related to the heat dissipation of soil which needs further research.

Experiment results show that energy efficiency coefficient of the ground source heat exchanger was decreased by time under both intermittent and continuous operating modes, but intermittent mode will enable system to rest during operation and promote system efficiency when starting again. So, it is believed that intermittent mode benefits the operation status of system at a high level of efficiency.. In continuous operation mode, in the second round of operation, reduction of inflow temperature from 35 to $32{ }^{\circ} \mathrm{C}$, leads into the decrease of temperature difference between ground source heat exchanger and the ground, which consequently reduces the energy efficiency coefficient of heat exchanger (Fig. 8). In intermittent alternative operation mode, since there is a period when the unit is not running, the heat energy accumulated in the ground was able to discharge to the surrounding areas. Therefore, the energy efficiency coefficient obtained in the intermittent alternative operation mode was higher than that in the continuous operation mode, from which it can be concluded that the intermittent operation can contribute to a higher energy efficiency of the ground source heat exchanger in heat pump systems.

The experiment results have shown that in both summer and winter seasons, the change of inflow temperature of buried ground source heat exchanger does 


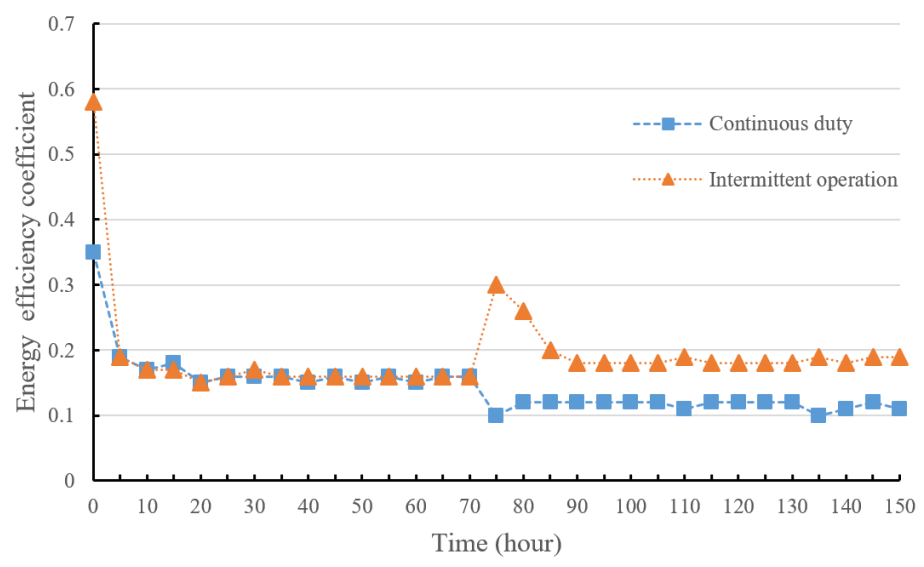

Figure 8: Energy efficiency coefficient of the vertical ground source heat exchanger under different operation modes

not have a significant influence on the energy efficiency coefficient of the heat exchanger. In addition, in long-term operation of the system in cooling mode, accumulation of heat in the ground is inevitable. This accumulated heat in the ground increases/decreases the temperature of the thermal fluid leaving the ground source heat exchanger as well as the condensing/operator temperature of the heat pump system, which significantly reduced the energy performance of the system. Therefore, in the design of ground source heat pump systems, considering an auxiliary cold/heat source can contribute to operation of the system at higher efficiency level due to the capability of the auxiliary system in offering the option for intermittent operation of the heat pump system.

\subsection{The influence of the type of buried tube to unit heat exchange}

Maintaining the temperature difference between inlet and outlet water at 10 ${ }^{\circ} \mathrm{C}$ and the flowrate is unchanged at $1200 \mathrm{~L} / \mathrm{h}$, it is found that the heat transfer of different types of buried pipes follows the same trend, but the heat exchange capacities of casing type and double- $\mathrm{U}$ shaped are higher than single- $\mathrm{U}$ type, as shown in Table 5 , 
Table 5: Heat exchange under different types of buried pipes

\begin{tabular}{cc}
\hline Type & Heat exchanged per meter $(\mathrm{W} / \mathrm{m})$ \\
\hline Casing-type & 39.1 \\
Double-U & 39.6 \\
Single-U & 32.5 \\
\hline
\end{tabular}
heat exchange effect but lead to higher capital cost.

The experiment results show that the energy efficiency coefficient of the 
ground source heat exchanger is reduced by time during the continuous opera-

\section{References}

[1] NDRC, Renewable Energy Development Plan for the Thirteenth Five Year Period, National Development and Reform Commission, China (2016).

[2] B. Li, R. Yao, Delivering sustainable built environments by an integrat380 ed approach, Renewable Energy 73 (2015) 1-2. doi:10.1016/j.renene. 2014.09 .016 
[3] S. Vares, T. Hkkinen, J. Ketomki, J. Shemeikka, N. Jung, Impact of renewable energy technologies on the embodied and operational ghg emissions of a nearly zero energy building, Journal of Building Engineering 22 (2019) 439-450. doi:10.1016/j.jobe.2018.12.017

[4] NDRC, 2007 Mid- and Long-Term Development Plan for Renewable Energy, National Development and Reform Commission, China (2007).

[5] X. Zhang, S. Chang, M. Eric, Renewable energy in china: An integrated technology and policy perspective, Energy Policy 51 (2012) 1-6. doi: 10.1016/j.enpol.2012.09.071.

[6] R. Sangi, D. Mller, Dynamic modelling and simulation of a slinky-coil horizontal ground heat exchanger using modelica, Journal of Building Engineering 16 (2018) 159-168. doi:10.1016/j.jobe.2018.01.005.

[7] G. Florides, S. Kalogirou, Ground heat exchangers-a review of systems, models and applications, Renewable Energy 32 (15) (2007) 2461-2478. doi : $10.1016 / j . r e n e n e .2006 .12 .014$.

[8] C. Li, J. Mao, X. Peng, W. Mao, Z. Xing, B. Wang, Influence of ground surface boundary conditions on horizontal ground source heat pump systems, Applied Thermal Engineering 152 (2019) 160-168. doi:10.1016/j. applthermaleng.2019.02.080.

[9] L. Zhao, T. Zhang, Q. Zhang, G. Ding, Influence of two systematic parameters on the geothermal heat pump system operation, Renewable Energy 28 (1) (2003) 35-43. doi:10.1016/S0960-1481(02) 00013-7.

[10] Z. Han, B. Li, S. Zhang, C. Bai, H. Hu, Study on design error of ground 405 source heat pump system and its influencing factors, Applied Thermal En-

口 gineering 144 (2018) 1030-1036. doi:10.1016/j.applthermaleng.2018. 09.010

[11] M. A. Bernier, Ground-coupled heat pump system simulation, Ashrae Transactions 107 (2001) 605-616. 
[12] T. You, X. Li, W. Wu, W. Shi, B. Wang, K. Soga, Coupled heating of ground-coupled heat pump system with heat compensation unit: Performance improvement and borehole reduction, Energy Conversion and Management 148 (2017) 57-67. doi:10.1016/j.enconman.2017.04.050.

[13] K. Wei, W. Li, J. Li, Y. Wang, L. Zhang, Study on a design method for hybrid ground heat exchangers of ground-coupled heat pump system, International Journal of Refrigeration 76 (2017) 394-405. doi:10.1016/j . ijrefrig.2016.12.020.

[14] Y. Shang, M. Dong, S. Li, Intermittent experimental study of a vertical ground source heat pump system, Applied Energy 136 (2014) 628-635. doi:10.1016/j.apenergy .2014.09.072.

[15] H. Zhou, J. Lv, T. Li, Applicability of the pipe structure and flow velocity of vertical ground heat exchanger for ground source heat pump, Energy and Buildings 117 (2016) 109-119. doi:10.1016/j.enbuild.2016.02.028.

[16] X. Zhai, M. Qu, X. Yu, Y. Yang, R. Wang, A review for the applications and 425 integrated approaches of ground-coupled heat pump systems, Renewable

(1) and Sustainable Energy Reviews 15 (6) (2011) 3133-3140. doi:10.1016/ j.rser.2011.04.024

[17] X. Wang, Y. Wang, Z. Wang, Y. Liu, Y. Zhu, H. Chen, Simulationbased analysis of a ground source heat pump system using super-long flexible heat pipes coupled borehole heat exchanger during heating season, Energy Conversion and Management 164 (2018) 132-143. doi: $10.1016 /$ j.enconman . 2018.03.001

[18] J. Luo, J. Rohn, M. Bayer, A. Priess, Modeling and experiments on energy loss in horizontal connecting pipe of vertical ground source heat pump 435 \astem, Applied Thermal Engineering 61 (2) (2013) 55-64. doi:10.1016/ j . applthermaleng.2013.07.022. 
[19] H. Esen, E. Turgut, Optimization of operating parameters of a ground coupled heat pump system by taguchi method, Energy and Buildings 107 (2015) 329-334. doi:10.1016/j .enbuild.2015.08.042.

[21] J. Chen, L. Xia, B. Li, D. Mmereki, Simulation and experimental analysis

[23] Y. Shang, S. Li, H. Li, Analysis of geo-temperature recovery under intermittent operation of ground-source heat pump, Energy and Buildings 43 (4) (2011) 935-943. doi:10.1016/j.enbuild.2010.12.017

[24] Q. Gao, M. Li, M. Yu, Experiment and simulation of temperature char455

[25] L. Zhang, G. Huang, Q. Zhang, J. Wang, An hourly simulation method for the energy performance of an office building served by a ground-coupled

[26] X. Zhai, X. Yu, Y. Yang, R. Wang, Experimental investigation and performance analysis of a ground-coupled heat pump system, Geothermics 48 (2013) 112-120. doi:10.1016/j.geothermics.2013.06.004. 
[27] Y. Man, H. Yang, J. Wang, Z. Fang, In situ operation performance test of ground coupled heat pump system for cooling and heating provision in temperate zone, Applied Energy 97 (2012) 913-920. doi:10.1016/j. apenergy.2011.11.049.

[28] H. Yang, P. Cui, Z. Fang, Vertical-borehole ground-coupled heat pumps: A review of models and systems, Applied Energy 87 (1) (2010) 16-27. doi:10.1016/j.apenergy.2009.04.038. 